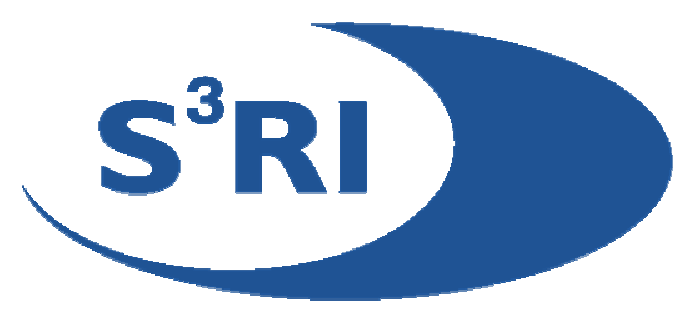

\title{
Poor Pregnancy Outcomes among Adolescents in South Nyanza Region of Kenya
}

\section{Monica Magadi}

\begin{abstract}
In this paper, we examine factors associated with poor pregnancy outcomes among teenagers in South Nyanza region of Kenya. The analysis is based on a recent WHO funded study on Adolescent safe motherhood in the region, which involved a survey of 1247 adolescents aged 12-19 and in-depth interviews with 39 of the adolescents who had experienced very early pregnancies or a pregnancy wastage. The indicators of poor pregnancy outcomes analysed include pregnancy wastage and premature delivery. A striking finding is the unusually high rate of premature deliveries, especially in cases of unintended pregnancies. Analysis of the qualitative data based on in-depth interviews sheds some light on possible explanations for the poor pregnancy outcomes observed among these adolescents. In particular, unsafe abortion attempts and poor maternal health care emerge as important issues of concern.
\end{abstract}

\section{$S^{3}$ RI Applications Working Paper A04/04}




\title{
Poor Pregnancy Outcomes among Adolescents in South Nyanza Region of Kenya
}

\author{
Monica Magadi \\ Opportunities and Choices Reproductive Health Research Programme, \\ Southampton Statistical Sciences Research Institute, \\ University of Southampton, U.K,
}

April 2004

\begin{abstract}
In this paper, we examine factors associated with poor pregnancy outcomes among teenagers in South Nyanza region of Kenya. The analysis is based on a recent WHO funded study on Adolescent safe motherhood in the region, which involved a survey of 1247 adolescents aged 1219 and in-depth interviews with 39 of the adolescents who had experienced very early pregnancies or a pregnancy wastage. The indicators of poor pregnancy outcomes analysed include pregnancy wastage and premature delivery. A striking finding is the unusually high rate of premature deliveries, especially in cases of unintended pregnancies. Analysis of the qualitative data based on in-depth interviews sheds some light on possible explanations for the poor pregnancy outcomes observed among these adolescents. In particular, unsafe abortion attempts and poor maternal health care emerge as important issues of concern.
\end{abstract}




\section{Introduction}

Notwithstanding the unresolved debate on the role of biological immaturity as opposed to social disadvantage in explaining poor birth outcomes among adolescents, studies in various settings of the world have established a positive association between teenage pregnancy and poor pregnancy outcomes such as low birth weight, premature births, and pregnancy wastage (Fraser et al., 1995; Wang \& Chou, 2003). A preterm birth is a major complication of teenage pregnancies, especially if the interval between menarche and conception is short (Treffers, 2003). In particular, younger adolescents aged under18 years have been observed to have the highest proportions of low birth weight, pre-term birth and infant mortality rate due to possible biological immaturity (Simoes et al., 2003; Da Silva et al., 2003) .

In the developing world, the problem of poor pregnancy outcomes among teenagers is further exacerbated by poor maternal health care among teenage mothers (Borja \& Adair, 2003). This is especially so in cases of unintended premarital pregnancies (Wang \& Chou, 2003; Magadi et al., 2000). The problem is particularly critical in sub-Saharan Africa where the incidence of adolescent pregnancies is highest, mainly due to lack of effective contraception for adolescents (Treffers, 2003) .

Despite the high prevalence of teenage pregnancies in Kenya, and associated adverse health and social consequences, studies addressing issues relating to maternal health among adolescents in the country are scarce. Existing population-based data suggest wide regional disparities in maternal health and adolescent reproductive health indicators in the country. Low maternal mortality ratios of less than 100 deaths per 100,000 live births have been observed in parts of the low mortality areas in central Kenya while ratios higher than 1000 deaths per 100,000 live births have been observed in some regions such as Nyanza, Coast and Western provinces (PSRI \& UNICEF, 1995). Nyanza Province has also consistently recorded the highest infant and child mortality levels in the country over last few decades. Indicators of maternal health do vary considerably even within Nyanza province. Among the 16 districts oversampled in the 1998 KDHS to provide district level estimates, contraceptive prevalence was lowest in South Nyanza (9.5\%, compared to $40.9 \%$ for Kisii within the same province). The same district (South Nyanza) also reported the lowest mean age at first intercourse (14.3 years), first marriage (16.0 years), and first birth (16.9 years), compared to national averages of 16.1, 18.4 and 18.8 years 
respectively (NCPD et al., 1999). Early initiation of sexual activity, in the absence of contraceptive use, exposes adolescents in such settings to particularly high risk of unplanned teenage pregnancies and related adverse outcomes. This paper analyses data from a recent WHO funded adolescent safe motherhood study in the South Nyanza region of Kenya to: (i) examine socio-economic and demographic factors associated with adverse pregnancy outcomes in South Nyanza; and (ii) explore possible explanations for poor pregnancy outcomes among teenagers in the region.

\section{Data and Methods}

This paper uses data from the adolescent safe motherhood survey (ASMS) of 2002. The survey involved interviews with 1247 adolescents aged 12-19 years from 3133 households in 32 clusters or communities. The data analyzed in this paper focuses on 269 completed pregnancies among 245 adolescents, reported in the pregnancy histories section of the questionnaire. Information on various maternal and pregnancy characteristics was obtained for each index pregnancy.This data is complemented with information from 39 in-depth interviews with a selected sample of these adolescents who had experienced very early pregnancies (at age 15 years or below) or unintended pregnancies that did not result in a live birth.

Pregnancy outcome is classified into three distinct categories: pregnancy wastage (abortions or still births); premature live birth and full term live births. The analysis of factors associated with pregnancy outcomes is based on both bivariate and multinomial regression analysis including a range of maternal and pregnancy characteristics relating to specific pregnancies, namely;

urban/rural residence; school enrolment status; educational attainment; maternal age; marital status; pregnancy order; desirability of pregnancy; timing and frequency of antenatal care; and place of delivery or pregnancy termination. The multinomial regression is carried out in two stages: the first model examines the net effects of background socio-economic and demographic factors, while the second model includes maternal health care variables in an attempt to establish potential pathways of the background determinants of poor pregnancy outcomes. 
The qualitative data from in-depth interviews is analysed by conducting a thematic content analysis. The data processing and analysis involved: coding and classifying responses; identifying key responses for various themes; and summarizing data to identify emerging patterns. Some excerpts from the in-depth interviews are presented verbatim to give a more detailed picture of the circumstances and consequences of teenage pregnancies in the study population.

\section{Preliminary Analysis}

\section{Pregnancy experience of survey respondents by background characteristics}

Of the total 1247 adolescents aged 12-19 interviewed, 245 (about 1 in 5) had ever been pregnant. The majority (181) of those who had ever been pregnant had experienced one pregnancy, while the remaining 64 had experienced two or more pregnancies. The distribution of pregnancy experiences by background characteristics is given in Table 1 .

\section{(TABLE 1 ABOUT HERE)}

The data presented in Table 1 show very strong associations between pregnancy experience and background characteristics of adolescents (except for district) all significant at 1 percent level based on Chi-square tests. About 30 percent of urban adolescents had experienced at least one pregnancy, compared to 16 percent of their counterparts residing in rural areas. The proportion of urban adolescents with 2 or more pregnancies is more than double that of rural adolescents (9 versus 4 percent).

As would be expected, pregnancy experience steadily increases with age of the adolescents. Only 3 percent of those aged 12-15 had ever been pregnant, while about 60 percent of the 18-19 year olds had ever been pregnant, with 22 percent in this age group reporting at least two pregnancies. Other sub-groups considerably more likely to have ever been pregnant include those living with spouses or not currently enrolled in school. Three-quarters of those living with a spouse, and about 55 percent of those out of school had ever been pregnant. It is important to recognize that these factors are interrelated. For instance, the older adolescents are more likely to be married 
and out of school. The distribution of pregnancy experience by household socio-economic status suggests that poverty is an important factor in teenage pregnancies.

Overall, the total number of reported pregnancies among the 245 ever pregnant adolescents ranges from 1 to 5, giving a total of 320 pregnancies, including current pregnancies. The analysis of pregnancy outcomes presented in the results section is based on 269 of these pregnancies that had ended by the time of the survey. Of the 245 ever pregnant adolescent, 86 met eligibility criteria for in-depth interviews (i.e experienced their first completed pregnancy at age 15 years or younger, or had an unintended pregnancy that did not result in a live birth). Forty-five of the eligible adolescents were targeted for in-depth interviews and successful interviews completed with 39 of them.

\section{Profile of in-depth interviewees}

The profile of in-depth interviewees, presented in Table 2 shows that the majority (27 out of 39) were living in rural areas. Almost all had attained only primary level education and were no longer enrolled in school. The majority were aged between 16 and 18 years, and married at the time of the survey. The typical age at first sex was between 12 and 15 years and first pregnancy experience was at age 14 or 15 years for all except four of the interviewees. The first pregnancy for six of the interviewees had ended in abortion or still birth. Twelve of the 39 adolescents had been pregnant more than once and all, except four, had at least one living child. Only 9 had ever used a family planning method.

\section{(TABLE 2 ABOUT HERE)}

\section{Results}

\section{Factors associated with poor pregnancy outcomes}

The bivariate associations between maternal and pregnancy characteristics with pregnancy outcomes are presented in Table 3.

(TABLE 3 ABOUT HERE) 
Overall, 7.5 percent of all reported pregnancies ended up in abortion or still birth, while the remaining 92 percent ended in live births, either prematurely or full term. An examination of the bivariate associations between socio-economic factors (urban/rural residence, school enrolment and educational attainment) and pregnancy outcomes (wastage, premature birth, full-term live birth) based on all the pregnancy histories shows that adolescents living in rural areas, not enrolled in school or with low educational attainment had a higher proportion experiencing pregnancy wastage compared to their counterparts who were living in urban areas, had higher educational attainment, or enrolled in school at the time of index pregnancy. Those in rural areas also had a higher proportion of premature births, compared to their urban counterparts.

With respect to demographic factors, relatively higher incidence of pregnancy wastage is observed among first pregnancies, pregnancies outside marriage and very young maternal age (15 years or younger). However, it is important to note that the associations between the socioeconomic and demographic characteristics with pregnancy outcomes are not statistically significant, possibly due to the relatively small number of pregnancies included in the analysis, and hence, insufficient power to detect some of the important associations.

Particularly striking is the strong association between desirability of a pregnancy and premature delivery $(\mathrm{p}=0.001)$. Unintended pregnancies are highly likely to result in a premature birth, compared to desired pregnancies. On the other hand, it is interesting to note that desired pregnancies are more likely to result in a pregnancy wastage than unintended pregnancies.

On the association between maternal health care and birth outcomes, the data show little evidence that poor maternal health care is associated with pregnancy wastage, except for the significant link between pregnancy wastage and fewer antenatal visits, presumably because some of these pregnancies only lasted a few months. However, the proportion of premature births is higher in cases where antenatal care was initiated late in pregnancy or where childbirth took place outside a health facility.

Multivariate analysis of the association between maternal and pregnancy characteristics with pregnancy outcomes is presented in Table 4. The first model (Model 1) focuses on the 
background socio-economic and demographic characteristics, while the second model (Model 2) includes the maternal health care variables to identify possible pathways of the background determinants of pregnancy outcomes.

\section{(TABLE 4 ABOUT HERE)}

The results of the multivariate analysis confirm the strong link between desirability of a pregnancy and premature delivery. The strong association persists after controlling for important socio-economic and demographic characteristics, as well as maternal health care variables. Another factor significantly associated with premature deliveries is place of delivery, with premature births being more likely to take place at home, compared to full-term births.

With respect to pregnancy wastage, marital status seems to be the significant factor. Pregnancies outside marriage are significantly more likely to result in an abortion or stillbirth than those within marriage, irrespective of whether the pregnancy is unintended or not. Even though desirability of pregnancy also shows marginal significance, the association is in the reverse direction, with unintended pregnancies being less likely to result in a wastage. This is possibly due to reporting bias. Similar observations had been made in an earlier study based on a different data set which noted that mothers were less likely to report a pregnancy as unintended if the index child was dead (Magadi, 2003).

\section{Possible explanations for poor pregnancy outcomes}

Analysis of the qualitative data from in-depth interviews begins to shed some light on possible explanations for the undesirable pregnancy outcomes, such as the unusually high rates of premature deliveries among teenagers in South Nyanza region, especially in cases of unintended pregnancies. Two important themes emerge from the in-depth interviews: poor maternal health care; and unsafe abortion attempts.

\section{Poor maternal health care}

One of the major problems facing adolescent mothers in South Nyanza region is poor accessibility of maternal health care services. In addition to the problem of physical accessibility, 
the appalling poverty situation aggregates the problem, making it impossible for the young mothers to seek approprite maternal health care, even in the most needy circumstances when complications, requiring urgent medical intervention develop, as illustrated by the excerpts below:

\section{Case 1}

"The next health center was so far, one had to walk for 5 to 6 hours to reach there. I also did not know the particular day when they provided the check ups. The alternative was to hire a bicycle or taxi to take me to the health centre (Magina) but I did not have the money

When the child was about to come out it suddenly moved back to the upper part of my stomach and refused to move back to the lower part of the stomach for a while ...The TBA added me more medicine to drink and after a short while the baby came out and died immediately “

\section{(Married at 15 years, pregnancy lasted 11 months, still birth)}

\section{Case 2}

...When I was almost to give birth , I was told at the clinic that the baby was sleeping in a wrong position(across the stomach). I was advised to go to Homabay District Hospital for delivery but I did not have any money, so I did not go

Q: $\quad$ For how long did the pregnancy last?

A: 12 months

Q: Why, did you have any idea why it was not the usual nine months?

A: Because it was a bleeding stomach. I told you that I used to bleed during the pregnancy. The TBA said that it was normal for a bleeding stomach to last for more than nine months

Q: $\quad$ So the bleeding was treated?

A: $\quad$ A TBA used to give me herbs to drink but it did not stop

Q: $\quad$ Where did the delivery take place?

A: Just here at home

Q: $\quad$ How was the delivery process, how long did the labour pains last?

A: $\quad$ Four days

Q: Where were you all this period?

A: I was at home with the TBA though I had problems up to the fifth day , the baby had not come out and they were very worried. I was also in great pain and the TBA gave me more medicine to drink but there was nothing happening. While they were making a stretcher to carry me to the roadside to take a vehicle to the hospital, God did to me a miracle- I suddenly delivered the baby

One astonishing feature of the two cases cited above is the unusually long gestation period. Although it is possible that this could have been compounded with reporting problems, since the teenagers may have been unable to determine the precise gestation period, most traditional birth attendants (TBAs) usually have reasonably accurate idea of the gestation period. In the first case, the pregnancy ended in a still birth possibly due to foetal distress. Although the second case resulted in a live birth, further interviews suggested that the pregnancy was most probably overdue since it was cited that "the baby looked miserable with wrinkled skin" at birth, a condition that is typical of postmaturity. This is an issue that no doubt warrants further investigation. One important question is: for how long can a complicated pregnancy requiring 
medical intervention in the form of a Caesarean section or induced labour possibly last in the absence of such medical intervention?

\section{$\underline{\text { Unsafe induced abortions }}$}

A substantial proportion of pregnancies among teenagers are unintended. These have considerable devastating effects on the girls, especially with respect to their educational opportunities and acceptance by the parents and families.

How did you feel when you realized you were pregnant?

R1: "I panicked, I was very afraid of what my parents would do to me. I ran away from school and came here to tell my boy friend" (aged 16 years, miscarried )

R2: "I was shocked and depressed" (married 17 year old, miscarried at 4 months, breastfeeding 8 month baby

R3: "I was very afraid and very unhappy because I feared what my parents would do to me. I was also wondering what I would do about school” (14 year old, induced abortion )

R4: "I felt bad because I was pregnant and my age mates were going to school (15 year old, attempted abortion failed, stillbirth)

In a number of cases, the teenagers are desperate to get out of the situation and often consider terminating the pregnancy. The excerpts below highlight typical cases of abortion being considered but decided against, unsuccessful and successful attempts, highlighting the commonly used procedures which are often unsafe and extremely risky.

Case 1

... I had even thought of aborting so that I go back to school. I was really worried

After second thoughts, I realized that the abortion could be harmful to my health and therefore decided otherwise

Q: How did you plan to abort?

A: Take medicine

A: Which one?

A: Some girls had told me earlier that one could take tea leaves

Q: What kind of tea leaves?

A: Strong very concentrated tea

Q: How was this prepared?

A: Boil water with tea leaves until it turns red and then drink it

Q: After taking it what happens?

A: Abortion takes place

Q: Did you ever tell anybody about this?

A: No, I just thought about it silently

Q: What changed your mind about the abortion?

A: From past experience there were some ladies who had had unsuccessful abortions and got hurt in the process. They were injured to death

Case 2

Q: Had you wanted to abort? 
A: Yes, I tried several times but I failed

Q: What did you do?

A: A girlfriend of mine advised me to buy a half litre of juice and drink it at once without diluting it

Q: Is that what you did?

A: Yes but it did not abort the fetus

Q: What did you do next?

A: She also advised me to buy a packet of tealeaves and drink. I tried this but failed again. Now my sister told me of another drug for injection

Q: What is its name?

A: I don't know what it's called

Q: Where did your sister get it?

A: She works as a subordinate in a certain health clinic. I pleaded with her, she agreed to buy the drug, and then she injected me

Q: How did this drug look like?

A: It is in a small bottle and looks white in colour and she bought it at 65 shillings

Q: What happened after the injection?

A: The abortion refused to take place

(16 year old, married after conceiving, looks thin/sickly, had child $<1$ year, pregnant with second child)

Case 3

A: I used to hear people saying that tea leaves helped in abortion, so I decided to try that.

Q: How did you go about it?

A: I just boiled some water one day while making breakfast, and then I put tealeaves on a sieve and passed a little hot water through it. Then I drank the resulting solution.

Q: And then what happened?

A: After drinking the solution, I felt nothing the whole day up to the evening is when there was a reaction. I even went to school normally, which was a Friday.

Q: What happened that evening?

A: My stomach started aching and this just intensified with every passing minute. Eventually even my mother became suspicious, but then it was too late and the foetus came out.

Q: You were still in the house when this happened?

A: Yes.

Q: Then what happened after that?

A: I was bleeding seriously so my mother went and bought me some medicine.

(15 year old, induced abortion, continued with schooling)

In most cases the abortion procedures involve very unsafe practices that greatly endanger the lives of these teenagers. Unsuccessful abortion attempts are likely to interfere with the normal gestation and health of the new born. Being aware and sometimes having witnessed the harmful effects of unsafe abortions, some decide to carry pregnancy to term and face the consequences of childbirth, rather than risk unsafe abortion which they knew could be fatal.

\section{Discussions and Conclusions}

The overall patterns in the associations between socio-economic and demographic characteristics with pregnancy outcomes observed in the bivariate and multivariate analyses conform to what is 
expected. The results show higher incidence of poor pregnancy outcomes among rural residents, those with low educational attainment, very young mothers, unmarried and first order pregnancies. However, these associations are not statistically significant, possibly due to the relatively small number of cases analysed in this paper, and hence, insufficient power to detect statistical significance.

One striking finding in this study is the unusually high incidence of premature deliveries, with about half of all live births reportedly premature. It is possible that the precise premature delivery rate is masked by reporting errors, since the information was based on mother's own report of gestation period which could have been inaccurate. Although other studies in sub-Saharan Africa have observed rather high premature delivery rates of up to 20 percent (Kulmala et al, 2000; Osman et al, 2001), the rates suggested in this study appalling, warranting further investigation. A number of factors may explain an unusually high rate of premature deliveries among adolescents in South Nyanza. The study area is predominantly inhabited by the Luo ethnic community, who had been observed in a separate study to have the highest incidence of premature deliveries in Kenya (Magadi et al., 2001). A study of unfavourable birth outcomes in Kenya observed that the odds of premature deliveries among Luo women was 7 times higher compared to the Kikuyu, and about 10 times higher compared to the other ethnic communities in Kenya combined (excluding Luhya, Kisii and Kikuyu). This suggests possible existence of some cultural practices that may be a risk factor to premature births among Luo women. The problem may be confounded with other health related factors including malaria, anaemia, and sexually transmitted infections, including HIV/AIDS, all known to be critical problems in the study region and important risk factors for premature deliveries. These factors, together with the fact that very young maternal age is in itself a risk factor for premature delivery (Simoes et al., 2003; Da Silva et al., 2003; Stevens-Simon et al., 2002), may partly explain the reported high incidence of premature deliveries among our study population.

The fact that the incidence of premature deliveries is particularly high among unintended pregnancies may be explained by a number of factors. First and foremost, unintended pregnancy has been identified as a risk factor for poor antenatal care which is in turn associated with premature deliveries (Magadi et al., 2001; Obor et al., 2003;Wang \& Chou, 2003) . However, this relationship persists even after controlling for antenatal care suggesting possible presence of 
other important factors. The qualitative information from the in-depth interviews highlight that some of the unintended pregnancies are subjected to repeated unsuccessful abortion attempts, which may possibly interfere with the normal gestation period. Nevertheless, it is important to recognize that the high rates of premature deliveries among unintended pregnancies may also be confounded with reporting problems, since the timing of pregnancies may be less accurate in cases of unintended, than intended pregnancies. However, the fact that no significant pattern is observed by education attainment or age may suggest this is unlikely to be a key explanation.

A related issue that may also be compounded with possible misreporting of the gestation period is the issue of overdue pregnancies. There are strong indications from the qualitative data that complicated pregnancies requiring critical medical intervention for safe delivery are unable to receive such care, with adverse consequences for maternal and newborn health due to postmaturity. Although the incidence of post-term pregnancy is believed to be low (less than $10 \%$ ) in most populations, it has been identified as a major cause of perinatal mortality (Jussmann et al. 1983).

The results from both the quantitative and the qualitative data illustrate urgent need for intervention in specific areas to improve pregnancy outcomes among teenagers in South Nyanza region. Of considerable concern is the problem of unintended pregnancies and associated problem of abortion and preterm deliveries. Another area of concern relates to accessibility of appropriate maternal health care, especially essential obstetric care and delivery care where both physical and cost barriers need to be addressed. Improving accessibility of reproductive health services for teenagers, including family planning and maternal health care, will undoubtedly go a long way in enhancing adolescent safe motherhood in the region. However, there is need for more in-depth understanding of the magnitude of the problem of premature and post-term deliveries in the region, possibly through medical research. Furthermore, there is need for better understanding of factors, including cultural practices, contributing to the unusually high incidence of premature deliveries in the study community, to enable formulation of most effective interventions to improve pregnancy outcomes, especially among adolescents in the region. 


\section{Acknowledgements}

This study is part of a project on adolescent safe motherhood in Kenya, funded by the WHO and implemented by the African Population and Health Research Centre, in collaboration with the DfID- funded Opportunities and Choices Reproductive Health Research Programme, of the University of Southampton, and the Population Studies and Research Institute of the University of Nairobi. 
Reference List

Borja, J. B. \& Adair, L. S. (2003). Assessing the net effect of young maternal age on birthweight. American Journal of Human Biology., 15,(6) 733-740

Da Silva, A. A. M., es, V. M. F., Barbieri, M. A., Bettiol, H., Lamy-Filho, F., Coimbra, L. C., \& Alves, M. T. S. S. (2003). Young maternal age and preterm birth. Paediatric and Perinatal Epidemiology., 17,(4) 332-339

Fraser, A. M., Brockert, J. E., \& Ward R.H. 1995 Association of young maternal age with adverse reproductive outcomes New England Journal of Medicine 332, 113-117

Jussmann, A., Wipff, J. and Morel B (1983) The overdue pregnancy, An easily preventable cause of perinatal mortality Reveu Francaise de Gynecologie et d Obstetrique 78(10), 615-618

Kulmala, T., Vaahtera, M., Ndeka, M, et al (2000) The importance of preterm births for peri-and neonatal mortality in rural Malawi Pediatr Perinat Epid 14, 219-226

Magadi, M (2003) Unplanned childbearing in Kenya: the socio-demographic correlates and the extent of repeatability among women Social Science and Medicine 56, 167-178

Magadi, M., Madise, N., \& Diamond, I. 2001 Factors associated with unfavourable birth outcomes in Kenya Journal of Biosocial Science 33, 199-225

Magadi, M. A., Madise, N. J., \& Rodrigues, R. N. 2000 Frequency and timing of antenatal care in Kenya: explaning the variations between women of different communities Social Science and Medicine 51, 551-561

NCPD, CBS, \& Macro International. 1999. Kenya Demographic and Health Survey, 1998 Caverton, Maryland., NCPD, CBS \& MI

Obor, V. O., Tabowei, T. O., Jemikalajah, J. J., Bosah, J. O., \& Agu, D. 2003. Pregnancy outcomes among nulliparous teenagers in suburban Nigeria. Journal of Obstetrics \& Gynaecology., 23,(2) 166-169

Osman, NB, Challis, K, Cotiro, M, Norhdal G, Beergstrom S (2001) Perinatal outcome in an obstetric cohort of Mozambican women $J$ Trop Pediatr 47, 30-38

PSRI \& UNICEF. 1995. 1994 Kenya Maternal Mortality Baseline Survey Nairobi, Kenya, Unpublished study report 
Simoes, V. M., Silva, A. A., \& Bettiol, H. 2003 Characteristics of adolescent pregnancy, Brazil Rev.Saude Publica 37[5], 559-565

Stevens-Simon, C., Beach, R. K., \& McGregor, J. A. 2002. Does incomplete growth and development predispose teenagers to preterm delivery? A template for research. Journal of Perinatology., 22,(4) 315-323

Treffers, P. E. 2003. Teenage pregnancie, a worldwide problem. [Dutch]. Nederlands Tijdschrift voor Geneeskunde., 147,(47) 2320-2325

Wang, C.-S. \& Chou, P. 2003. Differing risk factors for premature birth in adolescent mothers and adult mothers. Journal of the Chinese Medical Association, 66,(9) 511-517 
Table 1: Distribution of survey respondents by background characteristics and pregnancy experience

\begin{tabular}{|c|c|c|c|c|}
\hline \multirow[b]{2}{*}{ Background characteristic } & \multicolumn{3}{|c|}{ Pregnancy experience } & \multirow[b]{2}{*}{ Cases } \\
\hline & $\begin{array}{c}\text { Never } \\
\text { pregnant }\end{array}$ & $\begin{array}{c}\text { One } \\
\text { pregnancy }\end{array}$ & $\begin{array}{c}\text { Two or } \\
\text { more }\end{array}$ & \\
\hline \multicolumn{5}{|l|}{ District } \\
\hline - Homabay & 79.5 & 14.8 & 5.7 & 473 \\
\hline - Migori & 82.0 & 13.9 & 4.1 & 462 \\
\hline - Rachuonyo & 79.2 & 15.1 & 5.8 & 312 \\
\hline \multicolumn{5}{|l|}{ Current residence } \\
\hline - urban & 69.7 & 21.7 & 8.7 & 300 \\
\hline - $\quad$ rural & 83.7 & 12.2 & 4.0 & 947 \\
\hline \multicolumn{5}{|l|}{ Respondents age } \\
\hline - $12-15$ & 97.2 & 2.7 & 0.1 & 675 \\
\hline$-\quad 16-17$ & 75.7 & 21.2 & 3.1 & 325 \\
\hline$-\quad 18-19$ & 40.5 & 38.1 & 21.5 & 247 \\
\hline \multicolumn{5}{|l|}{ Whom respondent lives with } \\
\hline - $\quad$ both parents & 94.8 & 5.2 & 0.0 & 381 \\
\hline - $\quad$ father only & 94.1 & 5.9 & 0.0 & 34 \\
\hline - mother only & 96.5 & 3.2 & 0.4 & 283 \\
\hline - $\quad$ spouse & 24.9 & 51.5 & 23.6 & 233 \\
\hline - $\quad$ other & 88.0 & 9.5 & 2.5 & 316 \\
\hline \multicolumn{5}{|l|}{ Socio-economic status } \\
\hline - low & 76.6 & 16.0 & 7.4 & 376 \\
\hline - $\quad$ medium & 77.8 & 16.7 & 5.5 & 472 \\
\hline - high & 86.8 & 10.7 & 2.5 & 393 \\
\hline \multicolumn{5}{|l|}{ Currently in school } \\
\hline - yes & 98.4 & 1.6 & 0.0 & 818 \\
\hline - no & 45.5 & 39.3 & 15.2 & 422 \\
\hline \multicolumn{5}{|l|}{ Educational attainment } \\
\hline - $\quad$ none or primary incomplete & 82.3 & 12.6 & 5.1 & 975 \\
\hline - $\quad$ primary complete & 68.3 & 23.2 & 8.5 & 142 \\
\hline - $\quad$ secondary + & 79.2 & 19.2 & 1.5 & 130 \\
\hline All & 80.4 & 14.5 & 5.1 & 1247 \\
\hline
\end{tabular}


Table 2 : Socio-economic, demographic and reproductive health profile of in-depth interviewees by district

\begin{tabular}{|c|c|c|c|c|}
\hline \multirow{2}{*}{ Profile } & \multicolumn{3}{|c|}{ District } & \multirow[b]{2}{*}{ Total } \\
\hline & Homabay & Migori & Rachuonyo & \\
\hline \multicolumn{5}{|l|}{ Residence } \\
\hline - urban & 6 & 3 & 3 & 12 \\
\hline - $\quad$ rural & 11 & 9 & 7 & 27 \\
\hline \multicolumn{5}{|l|}{ Currently in school } \\
\hline - yes & 1 & 1 & 0 & 2 \\
\hline - no & 16 & 11 & 10 & 37 \\
\hline \multicolumn{5}{|l|}{ Educational attainment } \\
\hline - none /missing & 1 & 0 & 0 & 1 \\
\hline - $\quad$ primary 4 & 1 & 1 & 0 & 2 \\
\hline - $\quad$ primary 5 & 4 & 2 & 2 & 8 \\
\hline - $\quad$ primary 6 & 2 & 2 & 5 & 9 \\
\hline $\begin{array}{ll}\text { - } & \text { primary } 7\end{array}$ & 7 & 3 & 2 & 12 \\
\hline - $\quad$ primary 8 & 2 & 2 & 1 & 5 \\
\hline - Secondary 1 & 0 & 1 & 0 & 1 \\
\hline - $\quad$ Secondary 2 & 0 & 1 & 0 & 1 \\
\hline \multicolumn{5}{|l|}{ Living arrangement } \\
\hline - both parents & 1 & 3 & 1 & 5 \\
\hline - $\quad$ father only & 1 & 0 & 0 & 1 \\
\hline - $\quad$ mother only & 1 & 2 & 1 & 4 \\
\hline - $\quad$ spouse & 11 & 6 & 6 & 23 \\
\hline - $\quad$ other & 3 & 1 & 2 & 6 \\
\hline \multicolumn{5}{|l|}{ Current age } \\
\hline-14 & 0 & 1 & 0 & 1 \\
\hline-15 & 2 & 3 & 0 & 5 \\
\hline - 16 & 7 & 3 & 1 & 11 \\
\hline-17 & 4 & 2 & 3 & 9 \\
\hline-18 & 2 & 1 & 5 & 8 \\
\hline - 19 & 2 & 1 & 1 & 5 \\
\hline \multicolumn{5}{|l|}{ Age at first sex } \\
\hline-8 & 0 & 0 & 1 & 1 \\
\hline-9 & 0 & 1 & 0 & 1 \\
\hline-10 & 1 & 0 & 0 & 1 \\
\hline - 12 & 3 & 1 & 3 & 7 \\
\hline-13 & 2 & 4 & 1 & 7 \\
\hline - 14 & 4 & 4 & 1 & 9 \\
\hline-15 & 6 & 2 & 4 & 12 \\
\hline-16 & 1 & 1 & 0 & 1 \\
\hline \multicolumn{5}{|l|}{ Age at first pregnancy } \\
\hline-13 & 0 & 1 & 0 & 1 \\
\hline-14 & 3 & 4 & 2 & 9 \\
\hline-15 & 14 & 5 & 7 & 26 \\
\hline-16 & 0 & 1 & 0 & 1 \\
\hline-17 & 0 & 1 & 1 & 2 \\
\hline \multicolumn{5}{|l|}{ Outcome of first pregnancy } \\
\hline - abortion /stillbirth & 2 & 3 & 1 & 6 \\
\hline - $\quad$ live birth (premature) & 6 & 6 & 5 & 17 \\
\hline - $\quad$ live birth (full term) & 9 & 3 & 4 & 16 \\
\hline \multicolumn{5}{|c|}{ Number of times been pregnant } \\
\hline-1 & 12 & 9 & 6 & 27 \\
\hline-2 & 5 & 2 & 4 & 11 \\
\hline-3 & 0 & 1 & 0 & 1 \\
\hline \multicolumn{5}{|l|}{ Number of living children } \\
\hline-0 & 3 & 0 & 1 & 4 \\
\hline-1 & 11 & 7 & 6 & 24 \\
\hline-2 & 2 & 1 & 3 & 6 \\
\hline-3 & 0 & 1 & 0 & 1 \\
\hline \multicolumn{5}{|l|}{ Ever used family planning } \\
\hline - yes & 5 & 3 & 1 & 9 \\
\hline - no & 12 & 9 & 9 & 30 \\
\hline All Cases & 17 & 12 & 10 & 39 \\
\hline
\end{tabular}


Table 3: Distribution of pregnancy outcomes by maternal and pregnancy characteristics

\begin{tabular}{|c|c|c|c|c|}
\hline \multirow[b]{2}{*}{ Maternal/ pregnancy characteristics } & \multicolumn{3}{|c|}{ Pregnancy outcome } & \multirow[b]{2}{*}{ Cases } \\
\hline & Wastage & premature & Full term & \\
\hline \multicolumn{5}{|l|}{ Residence } \\
\hline - urban & 6.8 & 41.7 & 51.5 & 103 \\
\hline - $\quad$ rural & 7.9 & 49.4 & 42.1 & 164 \\
\hline \multicolumn{5}{|l|}{ School enrolment } \\
\hline - in school & 6.0 & 53.0 & 41.0 & 83 \\
\hline - $\quad$ out of school & 8.2 & 43.5 & 48.4 & 184 \\
\hline \multicolumn{5}{|l|}{ Maternal educational attainment } \\
\hline - $\quad$ none or primary incomplete & 8.9 & 45.5 & 45.5 & 191 \\
\hline - $\quad$ primary complete and above & 3.9 & 48.7 & 47.4 & 76 \\
\hline \multicolumn{5}{|l|}{ Maternal age } \\
\hline$-12-15$ & 10.8 & 45.8 & 43.4 & 83 \\
\hline$-\quad 16-17$ & 6.5 & 48.0 & 45.5 & 123 \\
\hline$-\quad 18-19$ & 4.9 & 44.3 & 50.8 & 61 \\
\hline \multicolumn{5}{|l|}{ Pregnancy order } \\
\hline - first pregnancy & 9.1 & 45.5 & 45.5 & 55 \\
\hline - $\quad$ second or higher & 7.1 & 46.7 & 46.2 & 212 \\
\hline \multicolumn{5}{|l|}{ Marital status } \\
\hline - married & 6.1 & 42.2 & 51.7 & 147 \\
\hline - $\quad$ unmarried & 9.2 & 51.7 & 39.2 & 120 \\
\hline \multicolumn{5}{|l|}{ Desirability of pregnancy*** } \\
\hline - desired & 11.1 & 27.8 & 61.1 & 72 \\
\hline - $\quad$ unintended & 6.2 & 53.3 & 40.5 & 195 \\
\hline \multicolumn{5}{|l|}{ Timing of first antenatal care } \\
\hline - $\quad$ first trimester & 9.1 & 38.6 & 52.3 & 44 \\
\hline - $\quad 2^{\text {nd }}$ or $3^{\text {rd }}$ trimester & 4.2 & 47.9 & 47.9 & 190 \\
\hline \multicolumn{5}{|l|}{ Frequency of antenatal visits* } \\
\hline - $\quad$ less than 4 & 8.5 & 45.4 & 46.2 & 130 \\
\hline - $\quad 4$ or more & 2.0 & 46.1 & 52.0 & 102 \\
\hline \multicolumn{5}{|l|}{ Place of delivery / termination** } \\
\hline - $\quad$ health facility & 7.8 & 37.1 & 55.2 & 116 \\
\hline - $\quad$ home /other & 7.3 & 53.6 & 39.1 & 151 \\
\hline- & & & & \\
\hline All & 7.5 & 46.4 & 46.1 & 267 \\
\hline
\end{tabular}

$*$ - $\mathrm{p}<0.1, * *-\mathrm{p}<0.05, * * *-\mathrm{p}<0,01$

Note: outcome of pregnancy missing for 2 cases, hence, total cases $=267$ rather than 269 
Table 4: Parameter estimates of pregnancy wastage and premature delivery, relative to full term live birth (Standard errors are given in brackets)

\begin{tabular}{|c|c|c|c|c|}
\hline \multirow[t]{2}{*}{ Parameter } & \multicolumn{2}{|c|}{ Model 1} & \multicolumn{2}{|c|}{ Model 2} \\
\hline & wastage & premature & wastage & premature \\
\hline \multicolumn{5}{|l|}{ Residence } \\
\hline - urban & $-0.29(0.532)$ & $-0.39(0.275)$ & $-0.36(0.563)$ & $-0.20(0.292)$ \\
\hline - rural $^{\mathrm{R}}$ & - & - & - & - \\
\hline \multicolumn{5}{|l|}{ School enrolment } \\
\hline - in school & $-0.96(0.690)$ & $-0.04(0.390)$ & $-0.91(0.696)$ & $-0.04(0.398)$ \\
\hline - $\quad$ out of school ${ }^{\mathrm{R}}$ & - & - & - & - \\
\hline \multicolumn{5}{|l|}{ Educational attainment } \\
\hline - $\quad$ none/pri incomplete & $0.78(0.690)$ & $-0.08(0.294)$ & $0.85(0.701)$ & $-0.27(0.316)$ \\
\hline - $\quad$ primary complete $+^{\mathrm{R}}$ & - & - & - & - \\
\hline \multicolumn{5}{|l|}{ Age group } \\
\hline$-\quad 12-15$ & $1.04(0.855)$ & $-0.14(0.440)$ & $0.94(0.876)$ & $-0.01(0.450)$ \\
\hline$-\quad 16-17$ & $0.50(0.784)$ & $0.05(0.375)$ & $0.42(0.803)$ & $0.16(0.383)$ \\
\hline$-\quad 18-19^{\mathrm{R}}$ & - & - & - & - \\
\hline \multicolumn{5}{|l|}{ Pregnancy order } \\
\hline - first pregnancy & $0.86(0.663)$ & $0.11(0.380)$ & $0.82(0.691)$ & $0.07(0.386)$ \\
\hline - $\quad 2^{\text {nd }}$ or higher ${ }^{\mathrm{R}}$ & - & - & - & - \\
\hline \multicolumn{5}{|l|}{ Marital status } \\
\hline - $\quad$ married & $-1.79(0.785)^{* *}$ & $-0.13(0.401)$ & $-0.76(0.819)^{* *}$ & $-0.04(0.412)$ \\
\hline - $\quad$ unmarried $^{\mathrm{R}}$ & - & - & - & \\
\hline \multicolumn{5}{|l|}{ Desirability of pregnancy } \\
\hline - desired then & $1.12(0.719)$ & $-1.08(0.352)^{* * *}$ & $1.26(0.744)^{*}$ & $-1.10(0.360)^{* * *}$ \\
\hline - $\quad$ unintended $^{\mathrm{R}}$ & - & - & - & - \\
\hline \multicolumn{5}{|l|}{ Antenatal care } \\
\hline - $\quad$ adequate $\left(1^{\text {st }}\right.$ trim, $4+$ visits $)$ & & & $-0.84(1.143)$ & $0.07(0.446)$ \\
\hline - inadequate $^{\mathrm{R}}$ & & & - & - \\
\hline \multicolumn{5}{|l|}{ Place of delivery/termination } \\
\hline $\begin{array}{ll}\text { - } & \text { home /other } \\
\text { - } & \text { health facility }\end{array}$ & & & $\begin{array}{c}-0.09(0.549) \\
-\end{array}$ & $0.72(0.291)^{* *}$ \\
\hline
\end{tabular}

